\title{
Knockout of Arabidopsis ACCELERATED-CELL-DEATH11 encoding a sphingosine transfer protein causes activation of programmed cell death and defense
}

\author{
Peter Brodersen, ${ }^{1,5}$ Morten Petersen, ${ }^{1,5}$ Helen M. Pike, ${ }^{3}$ Brian Olszak, ${ }^{1}$ Søren Skov, ${ }^{2}$ Niels Ødum, ${ }^{2}$ \\ Lise Bolt Jørgensen, ${ }^{4}$ Rhoderick E. Brown, ${ }^{3}$ and John Mundy ${ }^{1,6}$ \\ ${ }^{1}$ Institute of Molecular Biology, Copenhagen University, 1353 Copenhagen K, Denmark; ${ }^{2}$ Institute of Medical Microbiology \\ and Immunology, Copenhagen University, 2200 Copenhagen, Denmark; ${ }^{3}$ The Hormel Institute, University of Minnesota, \\ Austin, Minnesota 55912, USA; ${ }^{4}$ Botanical Institute, Copenhagen University, 1353 Copenhagen K, Denmark
}

\begin{abstract}
We describe the lethal, recessive accelerated-cell-death11 Arabidopsis mutant (acd11). Cell death in acd11 exhibits characteristics of animal apoptosis monitored by flow cytometry, and acd11 constitutively expresses defense-related genes that accompany the hypersensitive response normally triggered by avirulent pathogens. Global transcriptional changes during programmed cell death (PCD) and defense activation in acd11 were monitored by cDNA microarray hybridization. The PCD and defense pathways activated in acd11 are salicylic acid (SA) dependent, but do not require intact jasmonic acid or ethylene signaling pathways. Light is required for PCD execution in acd11, as application of an SA-analog to SA-deficient acd11 induced death in the light, but not in the dark. Epistatic analysis showed that the SA-dependent pathways require two regulators of SA-mediated resistance responses, PAD4 and EDS1. Furthermore, acd11 PR1 gene expression, but not cell death, depends on the SA signal tranducer NPR1, suggesting that the npr1-1 mutation uncouples resistance responses and cell death in acd11. The acd11 phenotype is caused by deletion of the ACD11 gene encoding a protein homologous to a mammalian glycolipid transfer protein (GLTP). In contrast to GLTP, ACD11 accelerates the transfer of sphingosine, but not of glycosphingolipids, between membranes in vitro.
\end{abstract}

[Key Words: Apoptosis; sphingosine; pathogenesis; senescence; signal transduction]

Received October 5, 2001; revised version accepted December 28, 2001.

In multicellular organisms, cell death occurs as necrosis or genetically defined programmed cell death (PCD). In necrosis, cells die in response to trauma and have little or no control over degenerative processes leading to death. In contrast, PCD is an active process that involves signaling pathways controlling the dismantling of the cell. In animals, the most common form of PCD is termed apoptosis. PCD in plants may share morphological characteristics with animal apoptosis such as condensation of nuclei, fragmentation of nuclear DNA, and cell shrinkage (Pennell and Lamb 1997).

PCD occurs in plants during various developmental processes and during interactions with pathogens. Examples of developmentally controlled PCD include senescence, sex determination in unisexual flowers, and

\footnotetext{
${ }^{5}$ These authors contributed equally to this work.

${ }^{6}$ Corresponding author.

E-MAIL mundy@biobase.dk; FAX 45-35322128.

Article and publication are at http://www.genesdev.org/cgi/doi/10.1101/ gad.218202.
}

the formation of the vascular system (Pennell and Lamb 1997). PCD in plant pathogen interactions is observed both during the hypersensitive response (HR) to avirulent infections and during the development of disease symptoms following virulent infections (Morel and Dangl 1997).

Cell death during HR is elicited by specific recognition of pathogen-derived molecules from avirulent pathogens by plant proteins encoded by resistance $(R)$ genes. Recognition is followed by local accumulation of reactive oxygen species (ROS), nitric oxide (NO), and salicylic acid (SA), that all potentiate resistance and pro-death pathways (Shirasu and Schultze-Lefert 2000). HR is accompanied by fortification of cell walls and accumulation of pathogenesis-related (PR) mRNAs and antimicrobial phytoalexins. These responses serve to protect the plant by restricting the growth of pathogens.

The control of HR cell death appears to involve the concerted action of both ROS and NO (Delledonne et al. 1998). The importance of SA has also been demonstrated 
in transgenic Arabidopsis expressing the bacterial SA hydroxylase (NahG), as depletion of SA abolishes an $R$ gene-mediated HR (Delaney et al. 1994). Although SA plays a crucial role in $H R$ and is sufficient for $P R$ gene accumulation and resistance (Ward et al. 1991), SA alone is insufficient to induce HR. The execution of HR cell death may involve proteolysis, as inhibitors of animal caspases reduce HR cell death (Pozo and Lam 1998).

Genetic approaches in Arabidopsis have been used to identify signaling components involved in HR control. Broadly, two different classes of mutants have been identified. The first includes mutants that fail to develop HR and resistance in response to infection by normally avirulent pathogens. Although many of these mutations identify R-genes (Ellis and Jones 1998), four different downstream regulators have also been identified by this approach. The lipase-like EDS1 and PAD4, and the putative 2TM protein NDR1 function at or downstream of the convergence of several different R-proteins (Aarts et al. 1998; Jirage et al. 1999), whereas the PBS1 protein kinase appears to be required specifically for AvrPphBelicited HR and resistance (Swiderski and Innes 2001).

The second group consists of mutants that develop HR-like lesions and activate defense responses in the absence of pathogens. These so-called lesion mimic mutants are represented by the $a c d$ - and $1 s d$-mutants (Dietrich et al. 1994; Greenberg et al. 1994; Weymann et al. 1995). Because of their constitutive HR/defense phenotype, lesion mimic mutants may define genes with regulatory roles in HR. Although this may not be correct in all cases (Molina et al. 1999), they serve as important tools to study PCD in plants. For example, much has been learned about SA and SA signal transducers in the death and defense pathways turned on in lesion mimic mutants. Thus, expression of the SA hydroxylase NahG rescues several lesion mimic mutants, whereas application of the SA-analogs benzo(1,2,3)thiadiazole-7carbothioic acid (BTH) or 2,6-dichloroisonicotinic acid (INA) restores lesioning in all but the $1 s d 7$ mutant (Weymann et al. 1995; Greenberg et al. 2000). These results demonstrate that PCD can be SA dependent. However, SA-independent cell death pathways also exist, as NahG expression does not abate lesions in $1 s d 2$ and $1 s d 4$ (Hunt et al. 1997) and exacerbates lesions in acd2 (Mach et al. 2001).
The role of the NPR1 ankyrin repeat protein in SAdependent cell death pathways has also been analyzed by use of acd-type mutants. NPR1 is required for responsiveness to exogenous SA (Cao et al. 1997), but, although loss of NPR1 function reduces lesion development in the acd5 mutant (Greenberg et al. 2000), cell death and defense activation occur independently of NPR1 in most lesion mimic mutants.

Of the many Arabidopsis cell death mutants described, six corresponding genes have been isolated. These genes fall into two general classes. The first defines genes involved in porphyrin metabolism (Molina et al. 1999; Ishikawa et al. 2001; Mach et al. 2001), whereas genes in the second class are involved in fatty acid metabolism (Mou et al. 2000; Kachroo et al. 2001). In addition, LSD1 encodes a zinc-finger protein proposed to negatively regulate a cell death pathway by monitoring a superoxide-dependent signal (Jabs et al. 1996; Dietrich et al. 1997).

Here, we report the characterization of the lethal, recessive acd11 Arabidopsis mutant, which exhibits characteristics of animal apoptosis and defense-related responses that accompany HR. The acd11 phenotype is SA dependent, as acd11 is rescued by nahG, and application of BTH to acd11/nahG restores cell death. This SA-mediated death pathway requires both functional PAD4 and EDS1, as the acd11 phenotype is suppressed by the pad4-2 and eds1-2 mutations. Molecular cloning, complementation, and lipid transfer assays revealed that ACD11 encodes a homolog of mammalian glycolipid transfer protein and has sphingosine transfer activity in vitro.

\section{Results}

\section{Identification and phenotype of the acd11 mutant}

The acd11 mutant was identified among stable transposant lines generated with a modified maize $D s$ element (Fig. 1A; Sundaresan et al. 1995). acd11 seed germinated with normal cotyledons, but developed chlorotic leaf margins at the two- to six-leaf stage. The chlorosis progressed and eventually engulfed the rosette before new leaves had fully expanded (Fig. 1A). This phenotype was equally strong in soil-grown plants at 16- and
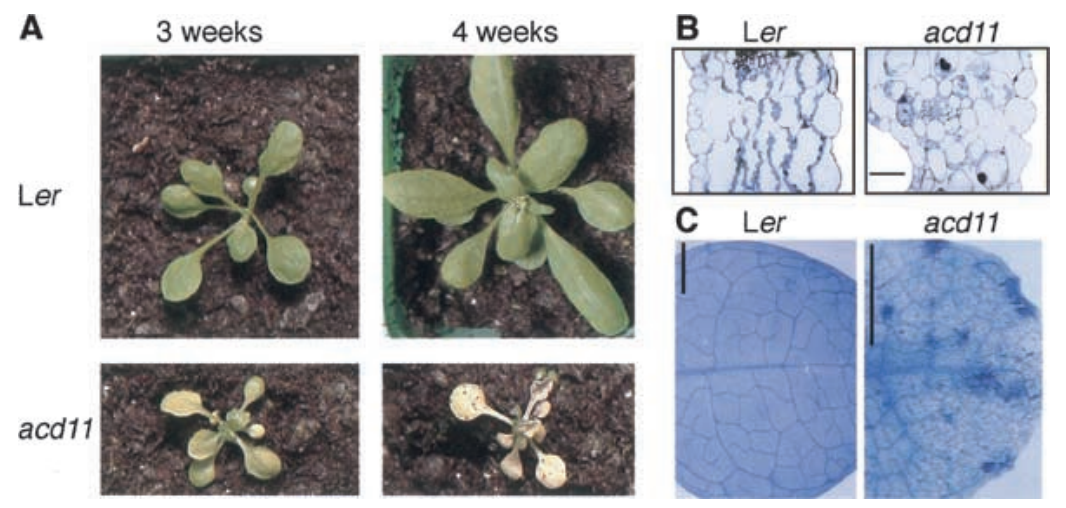

Figure 1. Phenotype of acd11 mutant. (A) Ler and acd11. (B) Cross sections of Ler and acd11 rosette leaves. Bar, $25 \mu \mathrm{m}$. (C) Trypan blue staining of Ler and acd11 rosette leaves. Bar, $25 \mathrm{~mm}$. 
8-h light cycles and in sterile-grown plants under continuous light. These results indicate that the phenotype was neither dependent on day length nor due to hypersensitivity to infection. The phenotype of acd11 segregated as a recessive trait. When acd11 plantlets survived long enough to initiate reproductive growth, flowers formed directly at the rosette, indicating that shoot formation is inhibited in acd11. In contrast, no obvious effect was observed on root growth in acd11 (data not shown).

Microscopic examination of acd11 rosette leaves revealed that overall cell size was normal. However, the plasma membrane of individual cells was separated from the cell wall (Fig. 1B). Compared with Ler controls, the acd11 mesophyll appeared disorganized and numerous cells contained clusters of wall material (Fig. 1B). In addition, numerous dead cells were seen microscopically by trypan blue staining (Fig. 1C).

\section{$P C D$ in acd11}

The type of cell death observed in acd11 could be necrosis due to basic cellular dysfunction. Alternatively, it might result from the execution of a cell death program activated as a consequence of the acd11 mutation. To distinguish between these two possibilities, we examined acd11 cell function in several ways. First, PCD is often preceded by a transient burst of reactive oxygen species (ROS; Pierce et al. 1991). To examine whether an oxidative burst is generated in acd11, mutants showing early symptoms were stained with nitro blue tetrazolium (NBT). The purple formazan precipitate produced by the reaction of NBT with superoxide was clearly visible throughout the leaves of acd11, but was absent in the Ler control (Fig. 2A).

Second, it is possible to measure apoptosis by flow cytometry through the use of the fluorescent dye 7-amino actinomycin D (7-AAD), which binds DNA. A selective decrease in DNA stainability is seen in apoptotic cells because of DNA condensation and/or cleavage. In addition, as acd11 cells are normal in size, apoptotic cell shrinkage can be detected because light scatter in the forward direction is proportional to cell size (Skov et al. 1997; Gòmez-Angelats et al. 2000). Figure 2B shows 7-AAD staining and cell sizes of Ler and acd11 protoplasts. A clear decrease in DNA stainability was observed in protoplasts isolated from acd11 compared with the Ler controls. Furthermore, a major fraction of acd11 protoplasts displayed low forward scatter values (Fig. 2B). This result suggests that the acd11 phenotype results from an active cell death program akin to animal apoptosis, rather than from necrosis.

Third, diphenylene iodonium (DPI), an inhibitor of the neutrophil NADPH oxidase, reduces lesion formation in 1sd1 when shifted to nonpermissive long-day conditions (Jabs et al. 1996), probably as a consequence of reduced production of ROS and NO (Delledonne et al. 1998). Accordingly, acd11 plants were treated with DPI for $48 \mathrm{~h}$ prior to protoplast isolation. Flow cytometry revealed a more than twofold decrease in the apparent apoptosis of acd11 compared to untreated controls (Fig. 2C).

Fourth, we examined the effects of the protein kinase inhibitor staurosporine and the phosphatase inhibitor okadaic acid on cell death in acd11 by treatments $48 \mathrm{~h}$ before protoplast isolation. Flow cytometry showed that both staurosporine and okadaic acid reduced acd11 cell death compared with untreated controls (Fig. 2C), further demonstrating that active participation of the cell regulatory machinery is required for acd11 cell death.

Fifth, accelerated cell death in acd11 might be the outcome of an early senescence program. Because cytokinins can inhibit the progression of leaf senescence (for review, see Gan and Amasino 1997), we examined whether cytokinin could block the progression of acd11

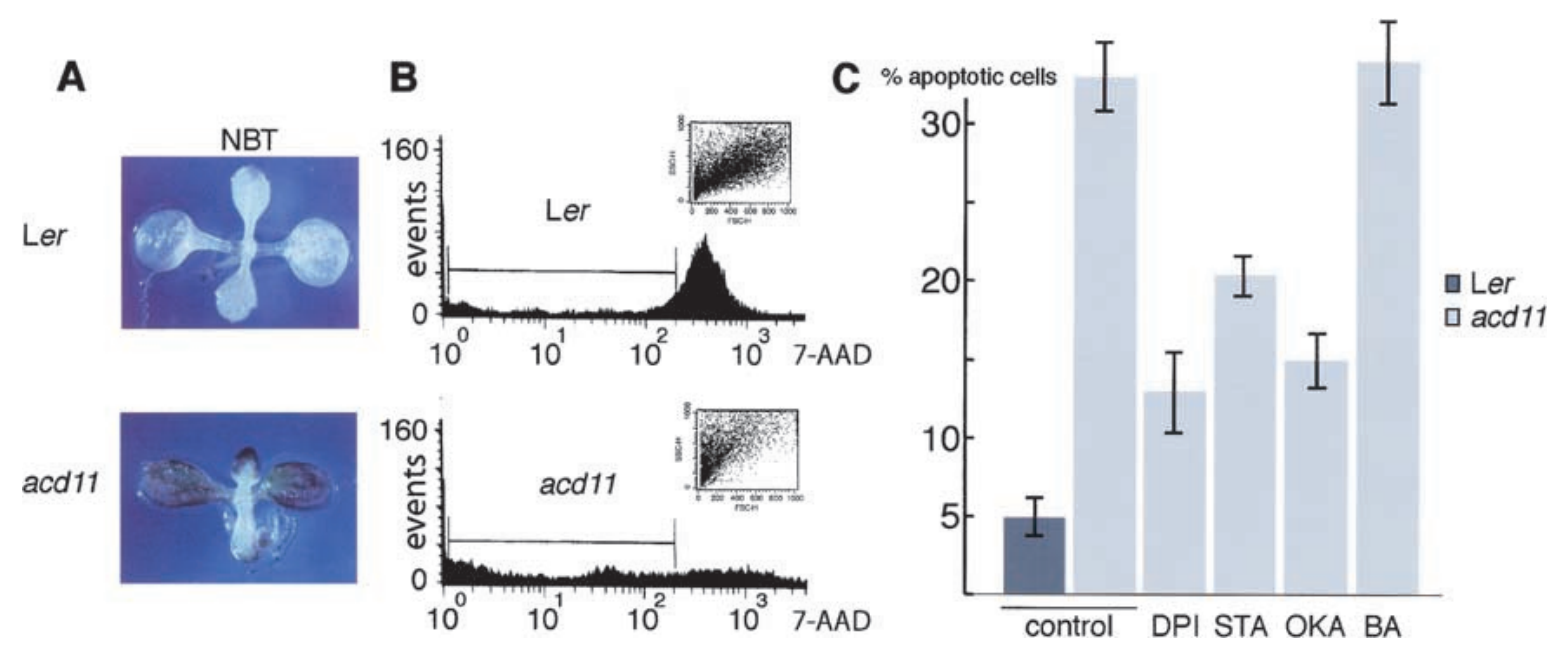

Figure 2. ROS and apoptosis measurements. (A) NBT staining of Ler and acd11 seedlings. (B) Flow cytometry of 7-AAD stained protoplasts isolated from Ler and acd11 rosette leaves showing number of cells (events) vs. 7-AAD intensity. Bars indicate fluorescence intensity intervals, which define apoptotic cells. (Inset) Side vs. forward scatter (cell size). Each experiment was repeated three times. (C) As in $B$ with diphenylene iodonium (DPI), staurosporine (STA), okadaic acid (OKA), or N(6)-benzyladenine (BA). 
cell death. Protoplasts were isolated from acd11 plants $48 \mathrm{~h}$ after treatment with the cytokinin N(6)-benzyladenine (BA) and from mock-treated acd11 plants. No discrepancy in the 7-AAD staining of DNA was observed between protoplasts from BA- and mock-treated acd11 plants (Fig. 2C). Therefore, the PCD pathway activated in acd11 is not likely to be related to senescence.

\section{acd11 expresses markers associated with $H R$}

Plant cells undergoing hypersensitive cell death produce and deposit secondary metabolites that are visible by their fluorescence. In addition, cell wall materials including callose and aromatic polymers are deposited at infection sites (Dietrich et al. 1994). Therefore, we examined acd11 leaves for the presence of autofluorescent material and stained for callose with aniline blue. Figure $3 \mathrm{~A}$ demonstrates that leaves of acd11 accumulate substantial amounts of autofluorescent products. Whole mounts of acd11 leaves showed a massive abundance of callose, whereas Ler controls only showed small patches of callose, primarily along the vein (Fig. 3A).

We also examined the expression of $P R$ genes in acd11, as other lesion mimic mutants constitutively express defense-related PR genes (Dietrich et al. 1994; Greenberg et al. 1994; Bowling et al. 1997). RNA blots verified that PR1, PR2, and PR5 were expressed constitutively in acd11 (Fig. 3B). In addition, transcripts of genes encoding proteins with roles in oxygen metabolism (peroxidase C, $P R X C)$, detoxification (glutathionine-S-transferase, GST) and synthesis of phenylpropanoid products (chalcone synthase, CHS) accumulate during HR and in lesion mimic mutants (Greenberg et al. 1994; Jabs et al. 1996). These transcripts also accumulated in acd11 (Fig. 3B).

Several genes are known to accumulate during senes-

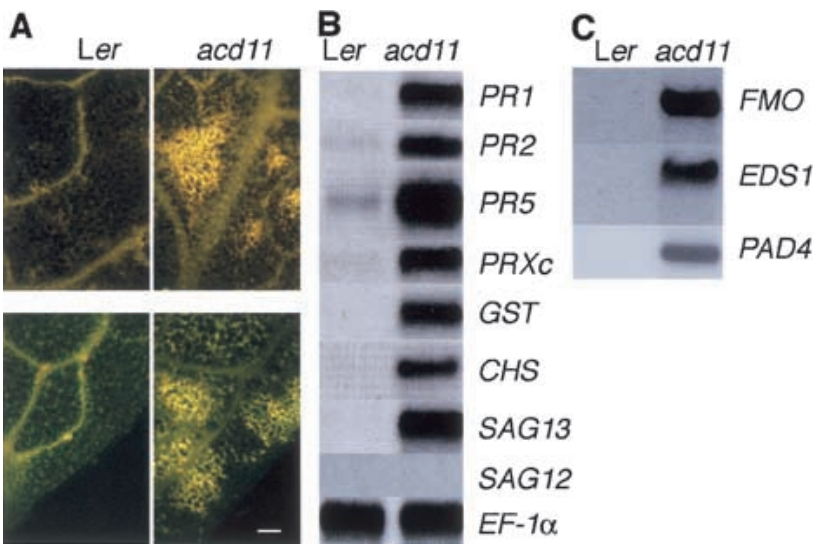

Figure 3. Accumulation of defense-related markers. $(A)$ Autofluorescence (top) and callose staining (bottom) of Ler and acd11 rosette leaves. Bar, $100 \mu \mathrm{M} .(B, C)$ RNA gel blots of $10 \mu \mathrm{g}$ total RNA hybridized with radiolabeled probes as indicated. The SAG12 probe detected $~ 1$ pg of the 1200-bp fragment used as a probe template spotted onto a filter. Equal loading of RNA was checked on all blots by hybridization with $E F-1 \alpha$. A representative blot is shown. cence including $S A G 12$, encoding a cysteine protease, and $S A G 13$, encoding a short-chain alcohol dehydrogenase (Lohman et al. 1994). Intriguingly, requirement for a short-chain alcohol dehydrogenase in plant PCD is observed during sex determination in the maize tasselseed2 mutant (DeLong et al. 1993). Therefore, we examined the expression of SAG12 and SAG13 in acd11. $S A G 13$ mRNA was strongly expressed in acd11, whereas SAG12 mRNA did not accumulate (Fig. 3B). The absence of SAG12 mRNA confirms that cell death in acd11 does not result from activation of a senescence program, whereas the strong expression of SAG13 suggests that this gene may serve as a PCD marker.

Consistent with their normal appearance, roots of acd11 did not have constitutive PR1- or SAG13-expression (data not shown).

\section{Patterns of global gene expression in acd11}

To expand our understanding of gene expression in acd11, we compared mRNA levels in acd11 and wildtype seedlings by cDNA hybridization to a microarray of 9861 cDNAs expressed throughout Arabidopsis development (Ruan et al. 1998). Of the 6820 (70\%) cDNAs that hybridized, 6374 hybridized at approximately equivalent levels in acd11 and wild type $93 \%$ between 2.5 -fold over- and underexpressed). Genes exhibiting significantly higher expression levels in acd11 (see Materials and Methods) were assigned to groups according to known or putative functions (Table 1). Although this list is not comprehensive, it clearly illustrates different patterns of gene expression.

The first group includes genes related to oxidative burst/stress and apoptosis. It includes mRNAs that accumulate during $\mathrm{HR}$, such as $P R X$ and GSTs, that were also detected by Northern hybridization (Fig. 3B). The overexpression of a flavin-containing monooxygenase (FMO) in acd11 is notable and was confirmed by Northern blotting (Fig. 3C). FMOs catalyze diverse reactions including the oxidation of $\mathrm{N}$ - and S-containing compounds (Ziegler 1993) and have not previously been associated with cell death and defense responses in plants.

The second group includes defense-related mRNAs that accumulate during resistance responses. For example, PR2 mRNA accumulated ninefold higher in acd11, consistent with the Northern results (Fig. 3B). In addition, the $P A D 3$ cytochrome $\mathrm{P} 450$ accumulates rapidly in infected tissue of wild type and is 15-fold induced in acd11. PAD3 is required for synthesis of the antimicrobial phytoalexin camalexin (Zhou et al. 1999). The production of camalexin also requires anthranilate synthase (ASA; Niyogi and Fink 1992), and ASA1 mRNA accumulation is up-regulated about fourfold in acd11. This group also includes the lipase-like gene EDS1 required for signaling from certain $R$-genes, and for accumulation of SA following virulent infection (Parker et al. 1996; Aarts et al. 1998). Constitutive expression of EDS1 was confirmed by Northern blotting (Fig. 3C).

The third group includes genes with putative signaling and regulatory functions. It includes the WRKY70 tran- 
Table 1. Genes >3.8-fold up-regulated in acd11

\begin{tabular}{|c|c|c|}
\hline G1 & Protein or homolog & $\begin{array}{l}\text { Fold up- } \\
\text { regulation }\end{array}$ \\
\hline \multicolumn{3}{|c|}{ Oxidative stress/burst and apoptosis } \\
\hline 8954062 & flavin-containing monooxygenase & 17.9 \\
\hline 443697 & glutathione-S-transferase (ERD11) & 16.7 \\
\hline 16202 & blue copper protein & 15.4 \\
\hline 407089 & glutathione- $S$-transferase & 8.7 \\
\hline 1402905 & peroxidase (PRXr2) & 6.6 \\
\hline 7270886 & DNA damage-inducible protein-like & 4.9 \\
\hline 8778278 & DNA break/repair protein-like & 4.7 \\
\hline 4432856 & dioxygenase & 4.0 \\
\hline \multicolumn{3}{|c|}{ Defense-related } \\
\hline 2288989 & chitinase & 16.2 \\
\hline 1167960 & extensin (EXT1) & 15.8 \\
\hline 15231632 & cytochrome P450 (PAD3) & 15.1 \\
\hline 903895 & pectin methylesterase (PME1) & 9.0 \\
\hline 166636 & $\beta$-(1,3)-glucanase 2 (PR2) & 8.7 \\
\hline 8777408 & myrosinase bd protein & 5.7 \\
\hline 457716 & CXc750 & 5.4 \\
\hline 4115363 & NBS-LRR R protein-like & 5.2 \\
\hline 3482931 & oxalate oxidase-like (GLP5) & 4.3 \\
\hline 166604 & anthranilate synthase (ASA1) & 4.3 \\
\hline 7269612 & stomatin-like & 4.2 \\
\hline 8954056 & pto responsive-like & 4.0 \\
\hline 4454567 & lipase/esterase (EDS1) & 3.8 \\
\hline 166638 & $\beta$-(1,3)-glucanase 3 (BGL3) & 3.8 \\
\hline \multicolumn{3}{|c|}{ Signal transduction and regulation } \\
\hline 8671834 & protein kinase/U-box & 11.2 \\
\hline 2244792 & methyl transferase/ankyrin repeat & 7.4 \\
\hline 4887748 & LRR receptor-like kinase & 7.1 \\
\hline 7594518 & transcription factor (WRKY70) & 6.9 \\
\hline 13430790 & calmodulin-like & 5.3 \\
\hline 598067 & calmodulin (TCH3) & 5.2 \\
\hline 7573467 & RING finger/VWA copine-like & 4.1 \\
\hline 7573430 & lipase/esterase & 4.1 \\
\hline 9957238 & ARF-GAP/C2 domains (ZAC) & 4.0 \\
\hline 1209633 & ARF-GEF (GNOM) & 4.0 \\
\hline \multicolumn{3}{|c|}{ Housekeeping } \\
\hline 2098712 & pectin esterase & 9.0 \\
\hline 13877696 & AAA ATPase & 8.4 \\
\hline 1805365 & xyloglucan endo-transglycosylase & 8.2 \\
\hline a & phosphoglycerate mutase-like & 7.7 \\
\hline 7529275 & FH bd-/ABA induced protein like & 7.3 \\
\hline 3319354 & hexose transporter-like & 5.4 \\
\hline 6017105 & cytochrome P450 & 5.2 \\
\hline 4587550 & exocyst subunit Exo 70-like & 5.0 \\
\hline 507946 & Asn synthetase (ASN1) & 5.0 \\
\hline 4544456 & cytochrome P450 & 4.6 \\
\hline 13374872 & mannosyl transferase-like & 4.3 \\
\hline 6650523 & RRM-motif RNA bd protein (MEI2) & 4.0 \\
\hline 1336083 & Glu dehydrogenase (GDH2) & 3.9 \\
\hline \multicolumn{3}{|l|}{ Others } \\
\hline 15219011 & unknown & 18.7 \\
\hline 6041793 & unknown & 13.1 \\
\hline 7269940 & unknown & 11.5 \\
\hline 8778226 & flavonol-induced protein like & 8.5 \\
\hline 4185135 & unknown & 7.8 \\
\hline 6850886 & contains C2 motif & 6.6 \\
\hline 10177080 & unknown & 6.4 \\
\hline 4432837 & unknown & 4.6 \\
\hline 3688186 & unknown & 4.5 \\
\hline 13430466 & acyl transferase-like & 3.9 \\
\hline 10177423 & unknown & 3.8 \\
\hline 3075398 & unknown & 3.8 \\
\hline
\end{tabular}

aNonannotated ORF on BAC F21M12; positions 118956-119026, 119363-119385, 119554-119664, 119849-119971. scription factor, a calmodulin, a receptor like-kinase $(R L K)$, a class IV U-box motif (Azevedo et al. 2001), and a RING finger motif-containing protein. WRKY transcription factors are plant-specific and regulate genes associated with pathogen defense. WRKY70 is closely related to two tobacco proteins, NtWRKY3 and NtWRKY4, that are induced by SA and pathogen infection /Chen and Chen 2000). Calmodulins may mediate HR-associated $\mathrm{Ca}^{2+}$ signals, as overexpression of calmodulin isoforms can induce lesions (Heo et al. 1999). Similarly, RLKs are rapidly induced in response to avirulent infections and may be involved in HR signaling (Du and Chen 2000), and this particular $R L K$ also accumulates in mpk4, which constitutively expresses SA-dependent defenses (Petersen et al. 2000). Both the U-box and the RING finger domains are involved in ubiquitination of target proteins for proteasomal degradation (Freemont 2000; Azevedo et al. 2001). In this respect, the up-regulation of an AAA motif ATPase is notable, as members of a large subgroup of this family function as components of the 26S proteasome (Patel and Latterich 1998).

The fourth group includes mRNAs that normally function in cellular housekeeping. Some encode enzymes involved in wall modifications, such as pectin esterase and xyloglucan endo-transglycosylases (XET), not previously implicated in HR-like responses, whereas the accumulation of a sugar transporter in acd11 is consistent with former reports (Schenk et al. 2000).

Table 2 lists mRNAs that accumulate to significantly lower levels in acd11 than Ler. The largest group includes genes involved in photosynthesis, which is not surprising given the chlorosis of acd11. The significance of the genes in the remaining three groups is speculative. However, the down-regulation of the cyclic nucleotide regulated ion channel is notable, because loss-of-function mutations in the homologous DND1 gene produce mutants with constitutive defense activation and conditional lesion formation (Clough et al. 2000). In addition, the repression of a MAP kinase phosphatase is consistent with reports of activation of MPK3 and MPK6 following oxidative stress (Kovtun et al. 2000) and of sustained MAP kinase activation after an HR inducing R-Avr recognition (Romeis et al. 1999).

\section{The acd11 phenotype is $S A$ and light dependent}

The development of PCD in lesion mimic mutants may be SA dependent (Weymann et al. 1995) or SA independent (Hunt et al. 1997; Mach et al. 2001). To examine whether SA accumulation is important for acd11 cell death, acd11 was crossed to nahG. Expression of nahG completely rescued the acd11 mutant, and although application of the SA analog BTH to acd11/nahG restored runaway cell death within $5 \mathrm{~d}$, wild-type Ler was unaffected by this treatment (Fig. 4A; data not shown).

To characterize further this SA-dependent pathway, acd11 was crossed to the pad4-2, eds1-2, and npr1-1 mutants. PAD4 and EDS1 encode lipase-like proteins that may function in an SA-amplification loop, as they are 
Table 2. Genes $>3.8$-fold repressed in acd11

\begin{tabular}{|c|c|c|}
\hline GI & Protein or homolog & $\begin{array}{l}\text { Fold down- } \\
\text { regulation }\end{array}$ \\
\hline \multicolumn{3}{|c|}{ Photosynthesis-related } \\
\hline 5734518 & PSI subunit III precursor & 5.7 \\
\hline 4741950 & LHC II antenna protein & 4.9 \\
\hline 9759044 & LipA-like & 4.8 \\
\hline 16367 & chlorophyll a/b bd protein & 4.7 \\
\hline 4741958 & PSII chlorophyll bd protein (Lhcb5) & 4.5 \\
\hline 3157944 & $\begin{array}{l}\text { GCV subunit } \mathrm{T} \\
\text { (aminomethyltransferase) }\end{array}$ & 4.3 \\
\hline 968976 & protochlorophyllide reductase & 4.1 \\
\hline 12083257 & chlorophyll a/b bd protein & 3.9 \\
\hline 1465365 & PS-II subunit $\mathrm{T}$ & 4.0 \\
\hline 16446 & PSII 10 kDa polypeptide & 4.0 \\
\hline 430946 & PSI chlorophyll bd protein $\left(\right.$ Lhca $\left.^{\star}{ }^{\star} 1\right)$ & 3.9 \\
\hline 4741959 & PSII chlorophyll bd protein (Lhcb6) & 3.9 \\
\hline \multicolumn{3}{|c|}{ Signal transduction and regulation } \\
\hline 217853 & DNA-bd HMG-box protein & 5.1 \\
\hline 435428 & GTP-bd protein & 4.3 \\
\hline 4581207 & $\begin{array}{l}\text { cyclic nucleotide/calmodulin-reg. } \\
\text { ion chl. }\end{array}$ & 4.1 \\
\hline 499161 & homeobox leucine zipper (HB-6) & 3.8 \\
\hline 6862915 & MAP kinase phosphatase & 3.8 \\
\hline \multicolumn{3}{|c|}{ Housekeeping and development } \\
\hline 166923 & ubiquitin carrier protein & 4.9 \\
\hline 9758220 & $(+)-\delta$-cadinene synthase & 4.6 \\
\hline 13877603 & contains EF1G and GST domains & 4.6 \\
\hline 4240120 & cytochrome b-5 & 3.9 \\
\hline 12323431 & metal-bd isoprenylated protein & 3.8 \\
\hline 16930501 & $\begin{array}{l}\text { thiazole biosynthesis enzyme } \\
\text { (ARA6) }\end{array}$ & 3.8 \\
\hline \multicolumn{3}{|l|}{ Other } \\
\hline 9758251 & unknown & 5.0 \\
\hline a & unknown & 4.8 \\
\hline
\end{tabular}

${ }^{\mathrm{a} N o n a n n o t a t e d ~ O R F ~ o n ~ B A C ~ T 1 E 4 ; ~ p o s i t i o n s ~ 3665-3895, ~ 4748-~}$ 4857.

transcriptionally induced by SA, but loss-of-function pad4 and eds1 mutants fail to accumulate SA after virulent and certain avirulent pathogen infections (Zhou et al. 1998; Falk et al. 1999; Jirage et al. 1999). Both pad4-2 and eds1-2 completely suppressed the acd11 phenotype (Fig. 4A). In addition, both EDS1 and PAD4 mRNAs accumulate in acd11 (Fig. 3C). However, although BTH application had an inhibitory effect on the growth of the shoot and leaf petioles, it did not restore lesion formation in acd11/eds1-2 and resulted in only sporadic cell death in acd11/pad4-2 (Fig. 4A). The difference between the effects of the eds1-2 and pad4-2 mutations on acd11 was confirmed by monitoring the expression of the SAG13 and PR1 markers $6 \mathrm{~d}$ after BTH application. Although acd11/pad4-2 expressed these markers almost as strongly as acd11/nahG, only weak expression was detected in acd11/eds1-2 (Fig. 4B).

In contrast to PAD4 and EDS1, the NPR1 ankyrin repeat protein acts downstream of SA (Cao et al. 1997). The size of acd11/npr1-1 double mutants was intermediate between acd11 and wild type, and although acd11/ npr1-1 developed chlorosis at about the same stage as acd11, acd11/npr1-1 leaves appeared paler than acd11 leaves (Fig. 4C). As in acd11, chlorosis spread and eventually engulfed the entire plant before seed set. Consistent with this death phenotype, expression of SAG13 in acd11/npr1-1 was as strong as in acd11 (Fig. 4D). In contrast, expression of the defense marker PR1 was nearly completely suppressed in acd11/npr1-1 (Fig. 4D). This result suggests that separable pathways leading to NPR1dependent $P R$ gene expression and NPR1-independent cell death are activated in acd11.

Apart from SA, the phytohormones ethylene and jasmonic acid (JA) have been shown to modulate PCD pathways (Asai et al. 2000). To examine JA and ethylene signaling in acd11 cell death, we constructed acd11/jar1-1 and acd11/ein2-1 double mutants. These double mutants fully retained the acd11 cell death phenotype (data not shown) and expressed PR1 and SAG13 to the same level as acd11 (Fig. 4E), indicating that intact ethylene and JA pathways are not required for acd11 cell death.

Light is a trigger of the $1 s d 1$ phenotype and is required for cell death in mutants defective in porphyrin metabolic pathways (Dietrich et al. 1994; Mach et al. 2001) and for PCD induced by the mycotoxin fumonisin B1 (FB1; Asai et al. 2000). To examine the effect of light on the acd11 phenotype, detached leaves of acd11/nahG were treated with BTH and kept in the light or in darkness for $4 \mathrm{~d}$. Although propagating cell death was absent in BTH-treated acd11/nahG leaves in the dark, PCD developed rapidly in the light (Fig. 4F).

\section{Cloning of ACD11}

Inverse PCR was used to isolate chromosomal sequences flanking both ends of the transposon in acd11. This approach showed that $D s$ had integrated on chromosome 2 in a position corresponding to BAC T29F13. Surprisingly, there was a $30-\mathrm{kb}$ gap between the matching chromosomal sequences, indicating that the transposon had created a $30-\mathrm{kb}$ chromosomal deletion upon insertion. This event was confirmed by PCR with acd11 and Ler genomic DNA templates and primer sets either outside or within the $30-\mathrm{kb}$ region. Although a fragment outside the $30-\mathrm{kb}$ region was amplified equally well from acd11 and Ler, no DNA could be amplified from acd11 with any of four different primer sets within the $30-\mathrm{kb}$ region (data not shown). Moreover, one end of the acd11 Ds locus (GI 3132469, pos. 50406) is identical to that of the T-DNA insertion in the original DsG1 donor line (Sundaresan et al. 1995; Parinov et al. 1999).

Linkage analysis indicated that the ACD11 gene is closely linked to, and possibly contained within, the 30$\mathrm{kb}$ deleted region (data not shown). This region contains five annotated genes (T29F13.7-T29F13.11). T29F13.11 is disrupted by the DsG1 donor T-DNA insertion, and, therefore, is not a candidate for $A C D 11$. For each of the four remaining genes, DNA fragments including $1500 \mathrm{bp}$ of 5' upstream and $500 \mathrm{bp}$ of $3^{\prime}$ downstream sequence were transformed into acd11 heterozygotes. Only T29F13.10 complemented the acd11 mutant, consistent with BAC subclone transformations that showed that 
Figure 4. Epistatic analyses. $(A)$ Phenotypes of mock- (left) and BTH- (middle) treated acd11/nahG, acd11/pad4-2, and acd11/eds1-2 plants $6 \mathrm{~d}$ after treatment. Trypan blue staining of BTH-treated leaves is also shown (right). (B) Accumulation of PR1 and SAG13 mRNA in mockand BTH-treated Ler, acd11/nahG, acd11/ pad4-2 and acd11/eds1-2 plants $6 \mathrm{~d}$ after treatment. At longer exposures, weak $P R 1$ and SAG13 signals are detected in BTHtreated acd11/eds1-2. (C) Phenotypes of acd11/npr1-1, acd11 and npr1-1 mutants. (D) Accumulation of PR1 and SAG13 mRNA in acd11/npr1-1, acd11 and npr1-1 mutants. $(E)$ Accumulation of PR1 and SAG13 in acd11/ein2-1, acd11/jar1-1 and in single mutants. $(F)$ Representative mock- or BTH-treated leaves of nahG and acd11/nah $G$ after $4 \mathrm{~d}$ in light or dark.
A mock

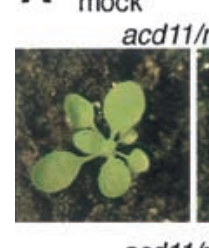

$100 \mu \mathrm{M} \mathrm{BTH}$

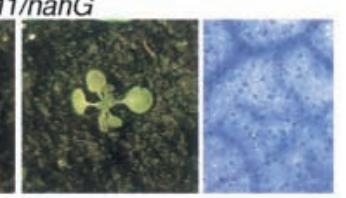

acd11/pad4-2

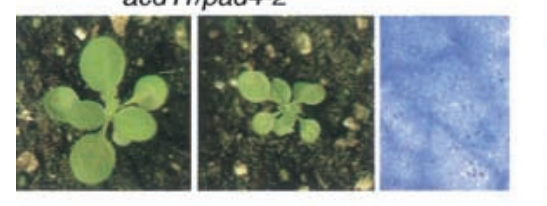

acd11/eds1-2
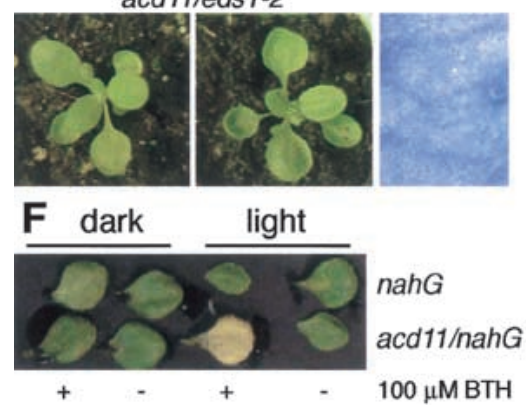

B
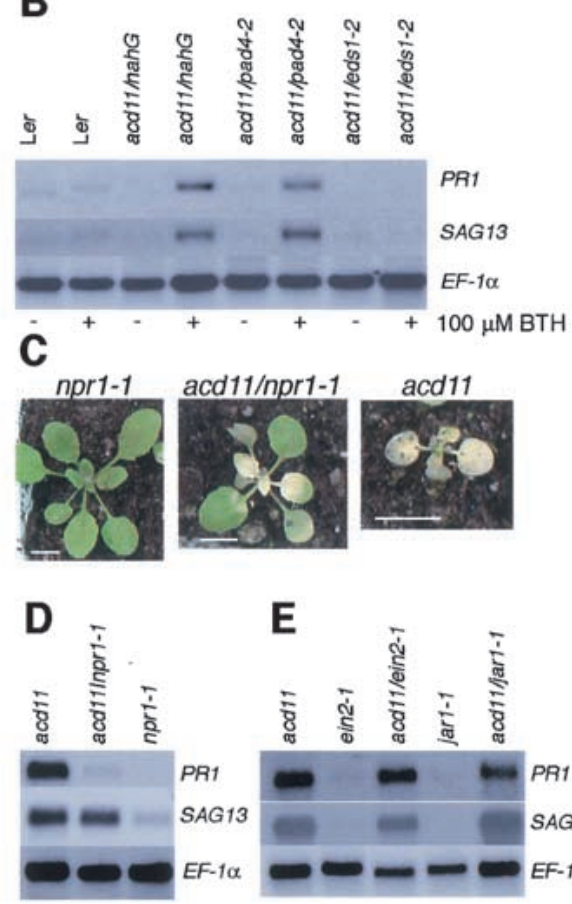

$\mathbf{E}$

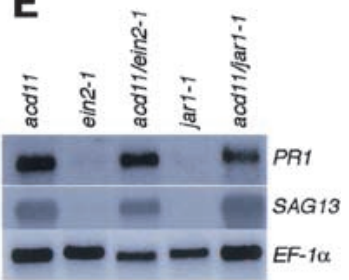

only a $15-\mathrm{kb}$ fragment spanning T29F13.10 complemented acd11 (data not shown). A full-length cDNA corresponding to T29F13.10 was obtained (EST 166P10T7) and cloned behind the strong viral 35S promoter. This construct also complemented acd11, demonstrating that T29F13.10 is the ACD11 gene.

\section{Sequence analysis of ACD11}

The coding region of the ACD11 cDNA confirmed the T29F13.10 annotation. ACD11 encodes a $22.7-\mathrm{kD}$ protein with no predicted transmembrane domains or localization motifs, suggesting that it is a cytosolic protein. ACD11 has two closely related homologs in rice and Arabidopsis, both of unknown function (Fig. 5A). Therefore, ACD11 belongs to a small family of proteins conserved in plants. More distantly related proteins were found in Drosophila melanogaster, Caenorhabditis elegans, different mammals, and in the ascomycete Podospora anserina (Fig. 5A). Most of these proteins are similar in length to ACD11, and their sequence similarities are found throughout the ACD11 sequence. In other cases, the ACD11-like sequence was part of a larger protein. Only two of the identified ACD11 homologs have been characterized. First, the nearly identical pig and bovine homologs catalyze the transfer of glycosphingo- and glycoglycerolipids between membranes in vitro, and, therefore, are called glycolipid transfer proteins (GLTP; Lin et al. 2000). However, the in vivo function of these proteins has not been rigorously established. The second is the P. anserina Het-C protein (Saupe et al. 1994). The multiallelic het-c locus is involved in specifying vegetative incompatibility, a process that impairs hyphal fu- sions of genetically different strains by triggering a lytic process reminiscent of animal PCD (Bégueret 1972).

\section{ACD11 has sphingosine transfer activity in vitro}

The homology of ACD11 to GLTP suggested that ACD11 may have lipid transfer or binding activity. Because sphingolipid-derived signals have been implicated in the regulation of PCD (Schmelz et al. 1998), we tested the ability of heterologously expressed ACD11 protein to catalyze the transfer of three different sphingolipids between vesicles in vitro, the GLTP substrate galactosylceramide (GalCer), ceramide (Cer), and sphingosine (Sph). Parallel transfer assays were carried out with recombinant GLTP protein purified by use of the same procedure as for ACD11. None of the proteins catalyzed Cer transfer, and although GLTP catalyzed GalCer transfer as expected, no such activity was observed for ACD11. In contrast, ACD11 had a small, but reproducible catalytic effect on the transfer of Sph, whereas Sph transfer in the presence of GLTP was equal to the background level (Fig. 5B,C). ACD11-stimulated Sph transfer was linearly dependent on ACD11 input in the range of 0.5-2.5 $\mu$ g, but further addition of ACD11 did not result in further stimulation of $\mathrm{Sph}$ transfer. To confirm ACD11 Sph transfer selectivity, transfer assays were repeated in the presence of bovine serum albumine (BSA), which has multiple binding sites for hydrophobic ligands. BSA did not affect ACD11 sphingolipid transfer specificity and only slightly increased ACD11 activity toward Sph (data not shown). Thus, the homologous ACD11 and GLTP proteins appear to differ in their sphingolipid transfer catalytic activities: GLTP acceler- 

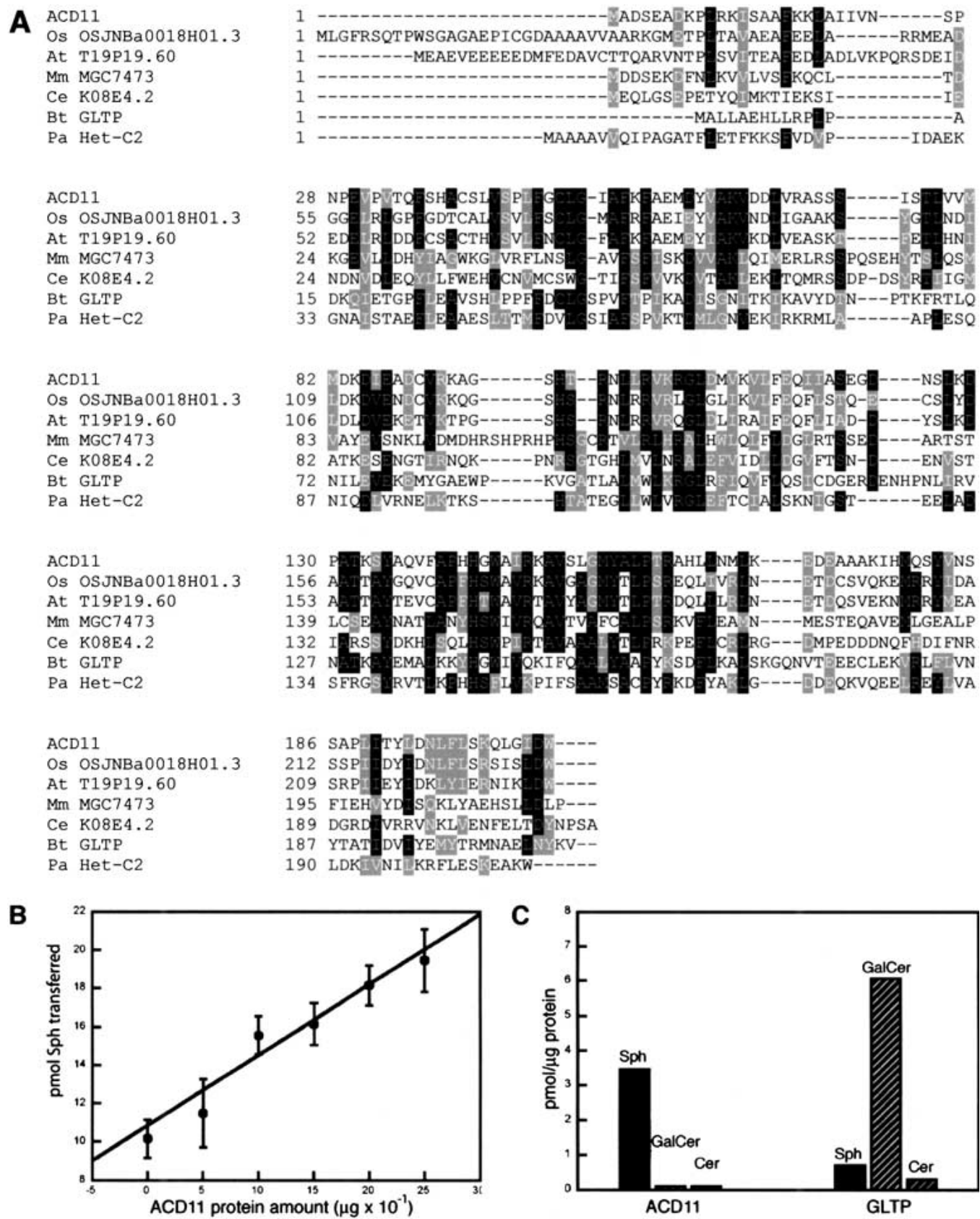

Figure 5. ACD11 is homologous to glycolipid transfer proteins and accelerates the transfer of sphingosine between membranes in vitro. (A) Alignment of ACD11 protein homologs of the same length as ACD11 ordered according to their similarity to ACD11. (Os) Oryza sativa; (At) A. thaliana; $(\mathrm{Mm})$ Mus musculus; $(\mathrm{Ce})$ C. elegans; $(\mathrm{Bt})$ Bos taurus; $(\mathrm{Pa})$ P. anserina. GI numbers corresponding to the proteins are OSJNBa0018H01.3, 13702819; T19P19.60, 7487218; MGC7473, 13277382; K08E4.2, 7505546; GLTP, 6959680; HetC2, 2133321. (B) Sphingosine transfer activity as a function of recombinant ACD11 input. (C) ACD11 and GLTP sphingolipid transfer specificity. The background transfer levels are subtracted from transfer in the presence of ACD11 or GLTP.

ates transfer of the complex sphingolipid GalCer, whereas ACD11 accelerates the transfer of the sphingoid base Sph.

\section{Discussion}

Both defense-associated and senescence-related pathways may lead to PCD in plant leaves. Cell death in acd11 probably does not proceed via a senescence-related pathway, because acd11 cell death could not be inhibited by cytokinin, and because mRNA of $S A G 12$, a reliable senescence marker, was not detected in acd11. These results and the defense activation data indicate that acd11 cell death occurs via a PCD pathway that is coordinated with the activation of defense responses. Such coordination of PCD and defense responses occurs both 
during HR and after virulent infections. In the plantpathogen system, these two types are readily separated by the speed, amplitude, and localization of activation. In contrast, it is difficult to distinguish between the two responses in a mutant such as acd11 with constitutive PCD/defense activation. Nonetheless, the independence of EIN2 argues that the PCD pathway activated in acd11 is different from that used during at least some susceptible pathogen interactions, as ein2 mutants showed a normal HR but developed less severe cell death symptoms upon virulent bacterial infections than wild type (Bent et al. 1992).

The clear PCD and defense activation phenotypes of the acd11 mutant prompted us to use this system to elucidate global transcriptional reprogramming during PCD and defense activation by microarray hybridization. As might be expected, this approach showed that photosynthesis-related genes were repressed, whereas numerous, well-known PCD and defense-associated transcripts were up-regulated in acd11. This observation argues that the changes detected by the microarray hybridization are reliable. Other genes with likely roles in PCD and defense, including FMO, XET, and pectin esterase, were also identified. In addition, previously uncharacterized genes were found to be differentially expressed in acd11. For example, the up-regulation of genes potentially involved in the ubiquitin-proteasome pathway raises interesting questions as to how their activities may contribute to PCD and defense activation and execution. Also, the correlation of sustained activation of the NtWIPK/AtMPK3 and NtSIPK/AtMPK6 MAP kinases during HR activation with the transcriptional downregulation of a MAPK phosphatase in acd11 suggests that one or both of these MAPKs could be in vivo substrates of this phosphatase.

In more general terms, the microarray results provide a list of genes related either causally or symptomatically to $\mathrm{PCD} /$ defense activation. Our genetic analysis with the eds1 and pad4 mutants indicates clearly that genes causally linked to PCD/defense are included in the list of up-regulated genes, but assignment of the remainder of the genes awaits studies by targeted gene disruption or identification through lesion mimic suppressor screens. Likewise, some of the genes repressed in acd11 may turn out to be $L S D$ or other $A C D$ genes, as indicated by the down-regulation of a cyclic nucleotide regulated ion channel homologous to the LSD gene DND1.

As in most other lesion mimic mutants, SA is a requisite modulator of the PCD pathways activated in acd11. Previous work has shown that the accumulation of SA in some $R$-gene dependent responses, such as RPP2 and RPP4 dependent responses, requires functional forms of both PAD4 and EDS1, whereas resistance triggered by other Arabidopsis $R$ genes does not (Glazebrook et al. 1997; Aarts et al. 1998;). Similarly, accumulation of SA and resistance in cpr1 require PAD4 and EDS1, whereas lesion formation and SA accumulation in cpr5 are largely PAD4 and EDS1 independent (Clarke et al. 2001; Jirage et al. 2001). These data indicate that PAD4 and EDS1 act at similar positions in specific pathways controlling SA accumulation. Our epistatic analyses suggest that loss of ACD11 turns on such a pathway upstream of PAD4 and EDS1, as acd11 phenotypes depend on SA accumulation as well as functional PAD4 and EDS1. Although restoration of massive cell death by treatment with the SA-analog BTH occurs in SA-deficient acd11/nahG, acd11/pad4-2 only exhibits sporadic cell death, and acd11/eds1-2 is nearly unaffected. Thus, analysis of the acd11 mutant clearly indicates that both EDS1 and PAD4 not only function in SA accumulation, but also control other signals that work in conjunction with SA to potentiate cell death. Two models may explain the different effects of pad4 and eds1 mutations. First, compared with PAD4, EDS1 may control a larger subset of other pro-death signals than SA, such that PCD activation in acd11/eds1-2 is more efficiently blocked than in acd11/pad4-2. Second, EDS1 or another homolog may partially compensate for loss of PAD4 function in the control of pro-death signals other than SA. Lastly, we note that because application of SA is sufficient to activate resistance responses in pad4 and eds1 (Falk et al. 1999; Jirage et al. 1999|, there may be different requirements for PAD4 and EDS1 in cell death and resistance responses.

What may be the function of ACD11? ACD11 does not appear to have an indispensable cellular function, such that loss of ACD11 function causes cells to collapse, because acd11 is suppressed by nahG. Thus, the acd11 phenotype is due to activation of signaling pathways dependent on SA that lead to PCD and defense activation. A major question is then whether the $\mathrm{Acd}^{-}$phenotype arises as a misinterpretation of an imbalanced biochemical state in the acd11 mutant, or whether ACD11 actually functions to negatively regulate PCD and defense in vivo. Although we are unable to distinguish clearly between these two possibilities, this question is pertinent to all lesion mimic mutants and has not been rigorously addressed in any case. Nonetheless, we note that large groups of genes differentially regulated in acd11 and wild type are related to death and defense activation and that well-defined groups of target genes for other hormonal or cellular responses could not be identified, indicating that the acd11 mutant is not excessively pleiotropic.

The in vitro sphingosine transfer activity of ACD11 provides a link between ACD11 function and sphingolipid metabolism. Sphingolipid biochemistry is connected to both plant and animal PCD, as the sphinganine-analog mycotoxins fumonisin $\mathrm{B} 1$ (FB1) and AAL toxin induce PCD in both plant and animal systems and competitively inhibit ceramide biosynthesis in vitro (Gilchrist 1997). In a colon-derived cell line, the PCDinducing effect of FB1 was shown to be mediated by the accumulation of the free sphingoid bases sphinganine and sphingosine (Schmelz et al. 1998). Also, AAL-susceptible, but not resistant tomato leaves accumulated high levels of free sphingoid bases when treated with AAL toxins (Abbas et al. 1994), presumably as a consequence of ceramide synthase inhibition.

In contrast to complex sphingolipids, sphingosine is able to move through the aqueous phase between mem- 
branes at appreciable rates on its own (Hannun et al. 2001), and, therefore, the physiological need for a sphingosine transfer protein is unclear. Nonetheless, a transfer protein may be required to rapidly sort sphingosine or other sphingoid bases in membrane compartments. Another possibility is that ACD11 functions as a cofactor for sphingoid base-modifying enzymes. This type of action is seen for other lipid transfer proteins. For example, the mammalian phosphoinositide transfer protein may function to supply substrates to phosphoinositide kinases (Cockcroft 1998). Elimination of such functions could lead to sphingoid base-mediated PCD activation. However, given that our survey of potential ACD11 sphingolipid substrates is not exhaustive and that the in vitro sphingosine transfer catalytic activity of ACD11 is relatively modest, we cannot rule out the possibility that physiological ACD11 substrates include sphingolipids other than sphingosine. Finally, we note that ACD11 homologs are found in multicellular eukaryotes capable of undergoing PCD, but not in the unicellular yeast Saccharomyces cerevisiae, arguing that ACD11 does not have a function in basic sphingolipid metabolism shared among all eukaryotes.

acd11 shares certain characteristics with PCD activation by FB1 in Arabidopsis, including dependence on light, SA accumulation, and functional PAD4, but not NPR1 (Asai et al. 2000). However, the genetic requirements for PCD activation are not identical, as FB1-induced cell death requires functional ethylene and JA signaling pathways, whereas both acd11/ein2-1 and acd11/ jar1-1 were $\mathrm{Acd}^{-}$. This observation suggests that either separate PCD pathways are activated in acd11 and upon FB1 treatment or that acd11 acts genetically downstream of JAR1 and EIN2. Preliminary results indicate that sphingosine levels are significantly higher in acd11 than in wild type, so both FB1 and ACD11 may lead to alterations in sphingoid base levels. If so, a biochemical interpretation would be that ethylene and jasmonate signaling are required to maintain perturbed sphingoid base metabolism upon FB1 treatment, but not in acd11. In any event, and regardless of whether ACD11 activity is used in vivo directly to regulate PCD, our results indicate that sphingolipid signaling is used to regulate PCD and defenses in plants.

\section{Materials and methods}

\section{Isolation of acd 11}

$\mathrm{F}_{3}$ progeny of transposant lines, generated in ecotype Ler according to Sundaresan et al. (1995), were examined phenotypically by growing 12 plants per line in soil.

\section{Histochemistry}

Leaf sections were fixed and embedded in Spuur's resin and stained with toluidine blue for cell walls and nucleic acids. Nitro blue tetrazolium and trypan blue staining were performed after Jabs et al. (1996) and Bowling et al. (1997). Callose and autofluorescence detections were performed after Dietrich et al. (1994).

\section{Apoptosis analysis}

Protoplasts were isolated from 16-day-old sterile-grown Ler and acd11 according to standard procedures. Protoplasts were pelleted, washed once in $2 \mathrm{~mL}$ of $0.03 \%$ saponin (S7900; Sigma) in PBS, and treated with $1 \mathrm{~mL}$ of $0.4 \mathrm{mg} / \mathrm{mL}$ 7-AAD (A9400; Sigma) in $0.03 \%$ saponin for $25 \mathrm{~min}$ at room temperature in the dark. Samples were analyzed immediately by flow cytometry in a FACScan (Becton Dickinson) using a logarithmic fluorescence scale. Treatments with either $5 \mu \mathrm{M}$ DPI, $0.1 \mu \mathrm{M}$ BA, $0.5 \mu \mathrm{M}$ staurosporine, or $0.1 \mu \mathrm{M}$ okadaic acid were performed by spraying plantlets $48 \mathrm{~h}$ prior to protoplasting.

\section{RNA analyses}

Total RNA was prepared for RNA gel blot hybridizations by use of standard protocols (RNAgentsTotal RNA, Promega). Probe templates were amplified by PCR from cDNAs or genomic DNA with primer sequences from PR1 (GI 3810599), PR2 (166636), PR5 (2435405), CHS (22983), SAG13 (6457348), FMO

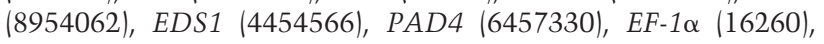
$P R X C$ (EST B25XP), and GST (EST 139F9T7). For cDNA microarray analysis, total RNA from $2 \mathrm{~g}$ of 14-day-old, sterile-grown wild type and acd11 was extracted by use of Trizol Reagent (Life Technologies). Poly(A) ${ }^{+}$RNA was purified from $200 \mu \mathrm{g}$ of total RNA with $2 \mu \mathrm{g}$ of Dynabeads Oligo(dT) ${ }_{25}$ (Dynal). cDNA microarray production, preparation of fluorescent probes, and microarray hybridization and scanning have been described (Ruan et al. 1998). In two independent hybridizations, $70 \%$ (1) and $14 \%$ (2) of the cDNAs on the microarray hybridized with intensities within the dynamic range. We attribute the relatively low total hybridization percentage in hybridization 1 to the fact that RNA from seedling rosette leaves was analyzed, and most (80\%) of the nonhybridizing clones were from root, stem, bud, or flower libraries. Although hybridization 2 was of low quality, it identified a set of differentially expressed genes contained within the larger set revealed in hybridization 1. Only hybridization 1 was used for further analysis, and data reported in Tables 1 and 2 are from this experiment.

After normalization of hybridization signals, the average $(0.00)$ and standard deviation $(0.20)$ of the $\log _{10}$-fold balanced difference between Ler and acd11 were calculated. This step enabled calculation of the frequency of random occurrences beyond a given log-fold balanced difference. In our case, the estimated frequency beyond $\pm 0.58 \log$-fold (3.8-fold up-regulated/ repressed, or 2.9 standard deviations) is $3.9 \times 10^{-3}$.

\section{Genetic analyses}

Homozygous nahG in ecotype Col-0 was crossed to heterozygous acd11 and $\mathrm{F}_{1}$ Ds heterozygotes identified by PCR. Of 255 $\mathrm{F}_{2}$ progeny, $20(1 / 13)$ exhibited the acd11 phenotype, indicating that the dominant nahG transgene suppresses acd11. This event was confirmed by PCR identification of acd11 homozygotes carrying nahG.

For analysis of crosses to eds1-2 and pad4-2, PCR-genotyped $D s$-heterozygous $\mathrm{F}_{1}$ plants were self-pollinated and $60 \mathrm{~F}_{2}$ seeds from each cross germinated in soil. Of these, 30 were sprayed with $100 \mu \mathrm{M}$ BTH. Plants exhibiting shoot inhibition after treatment were confirmed by PCR as homozygous for the acd11 and eds1-2 or pad4-2 alleles.

acd11/npr1-1 was constructed by CAPS-selection of npr1-1 homozygous $\mathrm{F}_{3}$ families by use of the NlaIII polymorphism of 
npr1-1. Families segregating putative acd11/npr1-1 were identified, and acd11/npr1-1 plants were shown by PCR and sequencing to be homozygous for npr1-1 and acd11.

acd11/ein2-1 and acd11/jar1-1 were constructed by selection of kanamycin-resistant $\mathrm{F}_{2}$ seedlings insensitive to $500 \mu \mathrm{M}$ ACC or $50 \mu \mathrm{M}$ MeJA, respectively. Roughly one-third of such plants had a typical acd11 phenotype, and surviving plants were heterozygous for KanR. Sequencing of EIN2 in acd11/ein2-1 confirmed that it was homozygous for the ein2-1 allele. jar1-1 homozygosity was confirmed in several lines by rechecking MeJA insensitivity of $\mathrm{F}_{3}$ families. Double mutants segregating from ACD11/acd11 ein2-1/ein2-1 and ACD11/acd11 jar1-1/jar1-1 families were used for expression analysis.

\section{Isolation and analysis of the ACD11 gene}

DNA from BAC T29F13 was prepared by Wizard Maxiprep (Promegal and digested with BamHI or SnaBI. The 21-kb BamHI fragment was cloned into pBIBACII (Hamilton 1997) whereas the $15-\mathrm{kb}$ SnaBI fragment was cloned into pCAMBIA3300. Single annotated gene fragments were PCR amplified from BAC T29F13 DNA template and cloned into pCAMBIA3300. To isolate the ACD11 cDNA, EST clones 166P10T7, 166I22T7, 215G14T7, and 162J7T7 were sequenced. 166P10T7 contained a full-length cDNA that was excised from pSPORT1 and cloned into VIP26 (Benfey et al. 1990). This cassette was subcloned into pCAMBIA3300 for transformation.

All constructs were transformed into ACD11/acd11 plants. Roughly $25 \%$ of transgenic $\mathrm{T} 1$ plants exhibited the acd11 phenotype except for those containing the 15-kb SnaBI fragment 18 out of 135), T29F13.10 (3 out of 181), and 35S-ACD11 (0 out of 31). For these three constructs, several phenotypically wild-type T2 lines homozygous for $D s$-carried kanamycin resistance were identified. Each was shown by PCR with primers specific for the four annotated genes deleted in acd11 to be acd11 homozygous, but to have the gene(s) carried on the respective T-DNAs. These lines segregated acd11 mutants, and such acd11 T2 plants were shown by PCR to lack the relevant transgene. ACD11 homologs were identified by BLASTP search of GenBank, aligned with ClustalW, and formatted using BOXSHADE.

\section{In vitro assay of sphingolipid intervesicular transfer}

The ACD11 cDNA was cloned into pGEX-5X-1 for protein expression. Both recombinant ACD11 and GLTP were produced as described previously (Lin et al. 2000), except that ACD11 was cleaved from GST with Factor-Xa (Pharmacia). A charged vesicle assay was used to monitor protein-mediated intermembrane transfer of radiolabeled sphingolipids (Brown et al. 1990, Mattjus et al. 2000). By the inclusion of negatively charged phospholipid in the donor vesicles, separation from neutral acceptor vesicles could be achieved after incubation with protein by elution through DEAE-Sephacel minicolumns. Both donors and acceptors were small unilamellar vesicles prepared by sonication (Barenholz et al. 1977) in transfer assay buffer $(10 \mathrm{mM}$ $\mathrm{Na}_{3} \mathrm{PO}_{4}$ at $\mathrm{pH} 7.4$ containing $1 \mathrm{mM}$ EDTA, $1 \mathrm{mM}$ DTT, and $0.02 \% \mathrm{NaN}_{3}$ ). Donors consisted of $88 \mathrm{~mol} \%$ 1-palmitoyl-2oleoyl phosphatidylcholine (POPC), 2 mol\% $\left[{ }^{3} \mathrm{H}\right]$ sphingolipid, $10 \mathrm{~mol} \%$ negatively charged dipalmitoyl phosphatidic acid, and a trace of nontransferable $\left[{ }^{14} \mathrm{C}\right]$ tripalmitin. Acceptor vesicles were comprised entirely of POPC. Each assay $(0.5 \mathrm{~mL})$ contained $0.2 \mu$ mole of donors, $2 \mu$ mole of acceptors, and protein. Incubations were typically performed at $37^{\circ} \mathrm{C}$ for $40 \mathrm{~min}$. prior to separation of donor and acceptor vesicles. $\left[{ }^{3} \mathrm{H}\right]$ sphingolipid transfer to recovered acceptor vesicles was quantitated by liquid scintillation counting as described by Brown and Thompson
(1987). Phospholipids and sphingolipids were obtained from Avanti Polar Lipids (Alabaster, MO) and Sigma-Aldrich (St. Louis, MO). Tritiated D-sphingosine was purchased from American Radiolabeled Chemicals (St. Louis, MO), tritiated galactosylceramide (galactocerebrosides, Sigma C1516) was synthesized as described by Brown and Thompson (1987), and tritiated ceramide ( $N$-palmitoyl-D-sphingosine) was produced by hydrogenation (Schwarzmann 1978).

\section{Acknowledgments}

We thank Suksawad Vongvisuttikun for technical assistance and the following for materials: The Arabidopsis Biological Resource Center (EST and BAC clones), X. Dong (npr1-1), J. Parker (pad4-2 and eds1-2), Nottingham Arabidopsis Stock Centre (ein2-1 and jar1-1), U. Neuenschwander, Syngenta (BTH). We thank The Monsanto Academic Arabidopsis program for performing cDNA microarray hybridizations and Henrik B. Nielsen for computational assistance. This work was supported by grants to J.M. from the Danish Biotechnology Program (9502002) and the European Union (QLq2CT199900351), to P.B. from the Danish Tennis Foundation, and to R.E.B. from the USPHS NIGMS (RO1-45928).

The publication costs of this article were defrayed in part by payment of page charges. This article must therefore be hereby marked "advertisement" in accordance with 18 USC section 1734 solely to indicate this fact.

\section{References}

Aarts, N., Metz, M., Holub, E., Staskawicz, B.J., Daniels, M.J., and Parker, J.E. 1998. Different requirements for EDS1 and $N D R 1$ by disease resistance genes define at least two $R$ genemediated signaling pathways in Arabidopsis. Proc. Natl. Acad. Sci. 95: 10306-10311.

Abbas, H.K., Tanaka, T., Duke, S.O., Porter, J.K., Wray, E.M., Hodges, L., Sessions, A.E., Wang, E., Merrill, A.H., and Riley, T.R. 1994. Fumonisin and AAL-toxin-induced disruption of sphingolipid metabolism with accumulation of free sphingoid bases. Plant Physiol. 106: 1085-1093.

Asai, T., Stone, J.M., Heard, J.E., Kovtun, Y., Yorgey, P., Sheen, J., and Ausubel, F.M. 2000. Fumonisin B1-induced cell death in Arabidopsis protoplasts requires jasmonate-, ethylene-, and salicylate-dependent signaling pathways. Plant Cell 12: 1823-1835.

Azevedo, C., Santos-Rosa, M.J., and Shirasu, K. 2001. The U-box protein family in plants. Trends Plant Sci. 6: 354-358.

Barenholz, Y., Gibbes, D., Litman, B.J., Goll, J., Thompson, T.E., and Carlson, F.D. 1977. A simple method for the preparation of homogeneous phospholipid vesicles. Biochemistry 16: 2806-2810.

Bégueret, J. 1972. Protoplasmic incompatibility: Possible involvement of proteolytic enzymes. Nature 235: 56-58.

Benfey, P.N., Ren, L., and Chua, N.H. 1990. Tissue-specific expression from CaMV 35 S enhancer subdomains in early stages of plant development. EMBO J. 6: 1677-1684.

Bent, A.F., Innes, R.W., Ecker, J.R., and Staskawicz, B.J. 1992. Disease development in ethylene-insensitive Arabidopsis thaliana infected with virulent and avirulent Pseudomonas and Xanthomonas pathogens. Mol. Plant-Microbe Interact. 5: 372-378.

Bowling, S.A., Clarke, J.D., Liu, Y., Klessig, D.F., and Dong, X. 1997. The cpr5 mutant of Arabidopsis expresses both NPR1dependent and NPR1-independent resistance. Plant Cell 
9: $1573-1584$.

Brown, R.E. and Thompson, T.E. 1987. Spontaneous transfer of ganglioside GM1 between phospholipid vesicles. Biochemistry 26: 5454-5460.

Brown, R.E., Jarvis, K.L., and Hyland, K.J. 1990. Purification and characterization of glycolipid transfer protein from bovine brain. Biochim. Biophys. Acta 1044: 77-83.

Cao, H., Glazebrook, J., Clarke, J.D., Volko, S., and Dong, X. 1997. The Arabidopsis NPR1 gene that controls systemic acquired resistance encodes a novel protein containing ankyrin repeats. Cell 88: 57-63.

Chen, C. and Chen, Z. 2000. Isolation and characterization of two pathogen and salicylic acid-induced genes encoding WRKY DNA-binding proteins from tobacco. Plant. Mol. Biol. 42: 387-396.

Clarke, J.D., Aarts, N. Feys, B.J., Dong, X., and Parker, J.E. 2001. Constitutive disease resistance requires EDS1 in the Arabidopsis mutants cpr1 and cpr6 and is partially EDS1-dependent in cpr5. Plant J. 26: 409-420.

Clough, S.J., Fengler, K.A., Yu, I., Lippok, B., Smith, R.K., and Bent, A.F. 2000. The Arabidopsis dnd1 "defense no death" gene encodes a mutated cyclic nucleotide-gated ion channel. Proc. Nat1. Acad. Sci. 97: 9323-9328.

Cockcroft, S. 1998. Phosphatidylinositol transfer proteins: A requirement in signal transduction and vesicle traffic. BioEssays 20: $423-432$.

Delaney, T.P., Uknes, S., Vernooij, B., Friedrich, L., Weymann, K., Negrotto, D., Gaffney, T., Gut-Rella, M., Kessmann, H., Ward, E., et al. 1994. A central role of salicylic acid in plant disease resistance. Science 266: 1247-1250.

Delledonne, M., Xia, Y., Dixon, R.A., and Lamb, C. 1998. Nitric oxide functions as a signal in plant disease resistance. $\mathrm{Na}$ ture 394: 585-588.

DeLong, A., Calderon-Urrea, A., and Dellaporte, S.L. 1993. Sex determination gene TASSELSEED2 of maize encodes a short-chain alcohol dehydrogenase required for stage-specific floral organ abortion. Cell 74: 757-768.

Dietrich, RA., Delaney, T.P., Uknes, S.J., Ward, E.R., Ryals, J., and Dangl, J.L. 1994. Arabidopsis mutants simulating disease resistance response. Cell 77: 565-577.

Dietrich, R.A., Richberg, M.H., Schmidt, R., Dean, C., and Dangl, J.L. 1997. A novel zinc finger protein is encoded by the Arabidopsis LSD1 gene and functions as a negative regulator of plant cell death. Cell 88: 685-694.

$\mathrm{Du}, \mathrm{L}$. and Chen, Z. 2000. Identification of genes encoding receptor-like protein kinases as possible targets of pathogenand salicylic acid-induced WRKY DNA-binding proteins in Arabidopsis. Plant J. 24: 837-847.

Ellis, J. and Jones, D. 1998. Structure and function of proteins controlling strain-specific pathogen resistance in plants. Curr. Opin. Plant Biol. 1: 288-293.

Falk, A., Feys, B.J., Frost, L.N., Jones, J.D.G., Daniels, M.J., and Parker, J.E. 1999. EDS1, an essential component of $R$ genemediated disease resistance in Arabidopsis has homology to eukaryotic lipases. Proc. Natl. Acad. Sci. 96: 3292-3297.

Freemont, P.S. 2000. Ubiquitination. RING for destruction? Curr. Biol. 10: R84-R87.

Gan, S., and Amasino, R.M. 1997. Making sense of senescence. Plant Physiol. 113: 313-319.

Gilchrist, D.G. 1997. Mycotoxins reveal connections between plants and animals in apoptosis and ceramide signaling. Cell. Death Diff. 4: 689-698.

Glazebrook, J., Zook, M., Mert, F., Kagan, I., Rogers, E.E., Crute, I.R., Holub, E.B., Hammerschmidt, R., and Ausubel, F.M. 1997. Phytoalexin-deficient mutants of Arabidopsis reveal that PAD4 encodes a regulatory factor and that four PAD genes contribute to downey mildew resistance. Genetics 146: 381-392.

Gomèz-Angelats, M., Bortner, C.D., and Cidlowski, J.A. 2000. Cell volume regulation in immune cell apoptosis. Cell Tissue Res. 301: 33-42.

Greenberg, J.T., Guo, A., Klessig, D.F., and Ausubel, F.M. 1994. Programmed cell death in plants: A pathogen-triggered response activated coordinately with multiple defense functions. Cell 77: 551-563.

Greenberg, J.T., Silverman, F.P., and Liang, H. 2000. Uncoupling salicylic acid-dependent cell death and defense related responses from disease resistance in the Arabidopsis mutant acd5. Genetics 156: 341-350.

Hamilton, C. 1997. A binary-BAC system for plant transformation with high-molecular-weight DNA. Gene 200: 104-116.

Hannun, Y.A., Luberto, C. and Argraves, K.M. 2001. Enzymes of sphingolipid metabolism. From modular to integrative signaling. Biochemistry 40: 4893-4903.

Heo, W.D., Lee, S.H., Kim, M.C., Kim, J.C., Chung, W.S., Chun, H.J., Lee, K.J., Park, C.Y., Park, H.C., Choi, J.Y., et al. 1999. Involvement of specific calmodulin isoforms in salicylic acid-dependent activation of plant disease responses. Proc. Natl. Acad. Sci. 96: 766-771.

Hunt, M.D., Delaney, T.P., Dietrich, R.A., Weymann, K.B., Dangl, J.L., and Ryals, J.A. 1997. Salicylate-independent lesion formation in Arabidopsis 1sd mutants. Mol. Plant-Microbe Interact. 10: 531-536.

Ishikawa, A., Okamoto, H., Iwasaki, Y., and Asahi, T. 2001. A deficiency of coproporphyrinogen III oxidase causes lesion formation in Arabidopsis. Plant J. 27: 89-99.

Jabs, T., Dietrich, R.A., and Dangl, J.L. 1996. Initiation of runaway cell death in an Arabidopsis mutant by extracellular superoxide. Science 273: 1853-1856.

Jirage, D., Tootle, T.L., Reuber, T.L., Frost, L.N., Feys, B.J., Parker, J.E., Ausubel, F.M., and Glazebrook, J. 1999. Arabidopsis thaliana PAD4 encodes a lipase-like gene that is important for salicylic acid signaling. Proc. Natl. Acad. Sci. 96: $13583-13588$.

Jirage, D., Zhou, N., Cooper, B., Clarke, J.D., Dong, X., and Glazebrook, J. 2001. Constitutive salicylic acid-dependent signaling in cpr1 and cpr6 mutants requires PAD4. Plant $T$. 26: $395-407$.

Kachroo, P., Shranklin, J., Shah, J., Whittle, E., and Klessig, D.F. 2001. A fatty acid desaturase modulates the activation of defense signaling pathways in plants. Proc. Natl Acad. Sci. 98: 9448-9453.

Kovtun, Y., Chiu, W.-L., Tena, G., and Sheen, J. 2000. Functional analysis of oxidative stress-activated mitogen-activated protein kinase cascade in plants. Proc. Natl. Acad. Sci. 97: 2940-2945.

Lin, X., Mattjus, P., Pike, H.M., Windebank, A.J., and Brown, R.E. 2000. Cloning and expression of glycolipid transfer protein from bovine and porcine brain. J. Biol. Chem. 275: 5104-5110.

Lohman, K.N., Gan, S., John, M.C., and Amasino, R.M. 1994. Molecular analysis of natural leaf senescence in Arabidopsis thaliana. Physiol. Plant. 92: 322-328

Mach, J.M., Castillo, A.R., Hoogstraten, R., and Greenberg, J.T. 2001. The Arabidopsis accelerated cell death gene ACD2 encodes red chlorophyll catabolite reductase and suppresses the spread of disease symptoms. Proc. Natl. Acad. Sci. 98: $771-776$.

Mattjus, P.M., Pike, H.M., Molotkovsky, J.G., and Brown, R.E. 2000. Charged membrane surfaces impede the protein-mediated transfer of glycosphingolipids between phospholipid bilayers. Biochemistry 39: 1067-1075. 
Molina, A., Volrath, S., Guyer, D., Maleck, K., Ryals, J., and Ward, E. 1999. Inhibition of protoporphyrinogen oxidase expression in Arabidopsis causes a lesion-mimic phenotype that induces systemic acquired resistance. Plant J. 17: 667678.

Morel, J.B. and Dangl, J.L. 1997. The hypersensitive response and the induction of cell death in plants. Cell Death Differ. 4: 671-683.

Mou, Z., He, Y., Dai, Y., Liu, X., and Li, J. 2000. Deficiency in fatty acid synthase leads to premature cell death and dramatic alterations in plant morphology. Plant Cell 12: $405-$ 417.

Niyogi, K.K. and Fink, G.R. 1992. Two anthranilate synthase genes in Arabidopsis: Defense-regulated regulation of the tryptophan pathway. Plant Cell 4: 721-733.

Parinov, S., Sevugan, M., Ye, D., Yang, W.C., Kumaran, M., and Sundaresan, V. 1999. Analysis of flanking sequences from dissociation insertion lines. A database for reverse genetics in Arabidopsis. Plant Cell 11: 2263-2270.

Parker, J.E., Holub, E.B., Frost, L.N., Falk, A., Gunn, N.D., and Daniels, M.J. 1996. Characterization of eds1, a mutation in Arabidopsis suppressing resistance to peronospore parasitica specified by several different RPP genes. Plant Cell 8: 2033-2046.

Patel, S. and Latterich, M. 1998. The AAA team: Related ATPases with diverse functions. Trends Cell Biol. 8: 65-71.

Pennell, I.P. and Lamb, C. 1997. Programmed cell death in plants. Plant Cell 9: 1157-1168.

Petersen, M., Brodersen, P., Naested, H., Andreasson, E., Lindhardt, U., Johansen, B., Nielsen, H.B., Lacy, M., Austin, M.J., Parker, J.E., et al. 2000. Arabidopsis MAP Kinase 4 negatively regulates systemic aquired resistance. Cell 103: 1111 1120.

Pierce, G.B., Parchment, R.E., and Lewellyn, A.L. 1991. Hydrogen peroxide as a mediator of programmed cell death in the blastocyst. Differentiation 46: 181-186.

Pozo, O. and Lam, E. 1998. Caspases and programmed cell death in the hypersensitive response of plants to pathogens. Curr. Biol. 8: 1129-1132.

Romeis, T., Piedras, P., Zhang, S., Klessig, D.F., Hirt, H., and Jones, J.D.G. 1999. Rapid Avr9- and Cf-9-dependent activation of MAP kinases in tobacco cell cultures and leaves: Convergence of resistance gene, elicitor, wound, and salicylate responses. Plant Cell 11: 273-287.

Ruan, Y., Gilmore, J., and Conner, T. 1998. Towards Arabidopsis genome analysis: Monitoring expression profiles of 1400 genes using cDNA microarrays. Plant J. 15: 821-833.

Saupe, S., Descamps, C., Turcq, B., and Bégueret, J. 1994. Inactivation of the Podospora anserina vegetative incompatibility locus het-c, whose product resembles a glycolipid transfer protein, drastically impairs ascospore production. Proc. Natl. Acad. Sci. 91: 5927-5931.

Schenk, P.M., Kazan, K., Wilson, I., Anderson, J.P., Richmond, T., Somerville, S.C., and Manners, J.M. 2000. Coordinated plant defense responses in Arabidopsis revealed by microarray analysis. Proc. Nat1. Acad. Sci. 97: 11655-11660.

Schmelz, E.M., Dombrink-Kurtzman, M.A., Roberts, P.C., Kozutsumi, Y., Kawasaki, T., and Merrill, A.H. 1998. Induction of apoptosis by fumonisin B1 I HT29 cells is mediated by the accumulation of endogenous free sphingoid bases. Toxicol. Appl. Pharmacol. 148: 252-260.

Schwarzmann, G. 1978. A simple and novel method for tritium labeling of gangliosides and other sphingolipids. Biochim. Biophys. Acta 529: 106-114.

Shirasu, K. and Schulze-Lefert, P. 2000. Regulators of cell death in disease resistance. Plant Mol. Biol. 44: 371-385.
Skov, S., Klausen, P., and Claesson, M.H. 1997. Ligation of major histocompatability complex (MHC) class I molecules on human $\mathrm{T}$ cells induces cell death through PI-3 kinase-induced c-Jun $\mathrm{NH}^{2}$-terminal kinase activity: A novel apoptotic pathway distinct from Fas-induced apoptosis. J. Cell Biol. 139: $1523-1531$

Sundaresan, V., Springer, P., Volpe, T., Haward, S., Jones, J.D.G., Dean, C., Ma, H., and Martienssen, R. 1995. Patterns of gene action in plant development revealed by enhancer trap and gene trap transposable elements. Genes \& Dev. 9: $1797-1810$

Swiderski, M.R. and Innes, R.W. 2001. The Arabidopsis PBS1 resistance gene encodes a member of a novel protein kinase subfamily. Plant J. 26: 101-112.

Ward, E.R., Uknes, S.J., Williams, S.C., Dincher, S.S., Wiederhold, D.L. Alexander, D.C., Ahl-Goy, P., Métraux, J.P., and Ryals, J.A. 1991. Coordinate gene activity in response to agents that induce systemic acquired resistance. Plant Cell 3: 49-59.

Weymann, K., Hunt, M., Uknes, S., Neuenschwander, U., Lawton, K., Steiner, H.Y., and Ryals, J. 1995. Suppression and restoration of lesion formation in Arabidopsis 1sd mutants. Plant Cell 7: 2013-2022.

Zhou, N., Tootle, T.L., and Glazebrook, J. 1999. Arabidopsis $P A D 3$, a gene required for camalexin biosynthesis, encodes a putative cytochrome P450 monooxygenase. Plant Cell 11: 2419-2428.

Zhou, N., Tootle, T.L., Tsui, F., Klessig, D.F., and Glazebrook, J. 1998. PAD4 functions upstream from salicylic acid to control defense responses in Arabidopsis. Plant Cell 10: 10211030.

Ziegler, D.M. 1993. Recent studies on the structure and function of multisubstrate flavin-containing monooxygenases. Annu. Rev. Pharmacol. Toxicol. 33: 179-199. 


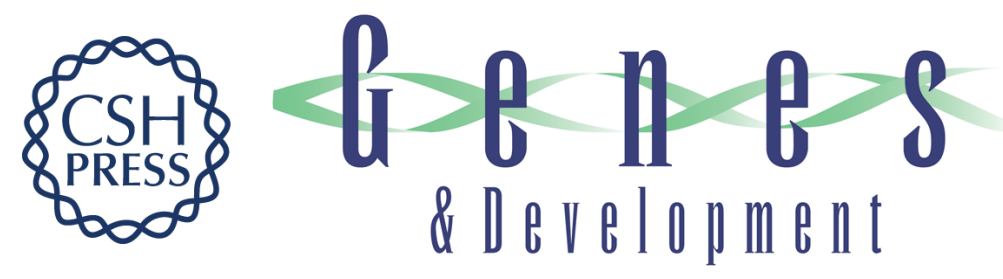

\section{Knockout of Arabidopsis ACCELERATED-CELL-DEATH11 encoding a sphingosine transfer protein causes activation of programmed cell death and defense}

Peter Brodersen, Morten Petersen, Helen M. Pike, et al.

Genes Dev. 2002, 16:

Access the most recent version at doi:10.1101/gad.218202

References This article cites 69 articles, 30 of which can be accessed free at: http://genesdev.cshlp.org/content/16/4/490.full.html\#ref-list-1

License

Email Alerting

Receive free email alerts when new articles cite this article - sign up in the box at the top Service right corner of the article or click here.

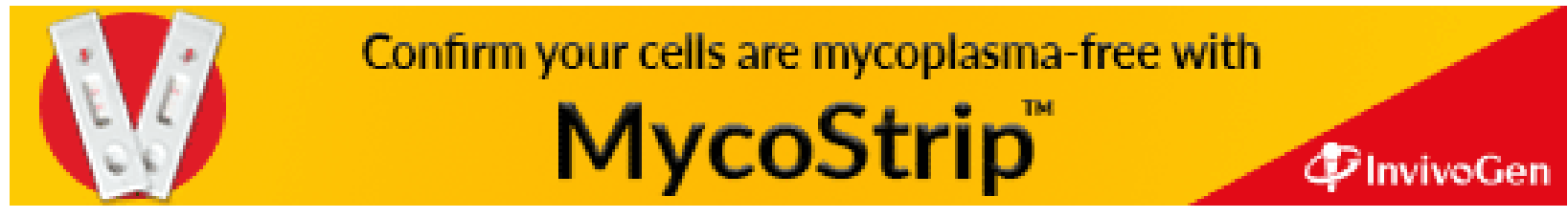

